\title{
A Case Review of a Male Chinese Savant Adult with Tuberous Sclerosis Complex and Syndromic Low-Functioning/Non-verbal Autism
}

\author{
-Lyndsey Aik Lwee Goh: Twinkle Intervention Center, Singapore.
}

Guohui Xie: i-Disability \& Disorder Diagnostics Clinic (i-DDDC), KL, Malaysia.

\begin{abstract}
This is a case review of a male Chinese adult, BK, who has been previously diagnosed with tuberous sclerosis complex, syndromic low-functioning/non-verbal autistic savantism and intellectual disability. He has the gift of painting and has since produced many works that show he has an eye for detail, color, texture, and stroke application (Camulli, Goh and Chia, 2018). This paper adopts a different perspective to study the case by re-examining BK's systemizing ability, i.e., his innate drive to analyze or construct any kind of system, and in his case, painting. Systemizing is defined as the ability to follow a certain set of implicit rules that is governing the system in order to predict how that system will behave (Baron-Cohen 2006). In BK's case, the focus is on his gift of systemizing ability in the cognitive process of acrylic painting using the following cognitive formulation: [input] $\rightarrow$ [operation] $\rightarrow$ [output].
\end{abstract}

Key words: Autism, Savant, Systemizing, Systems, Tuberous sclerosis complex.

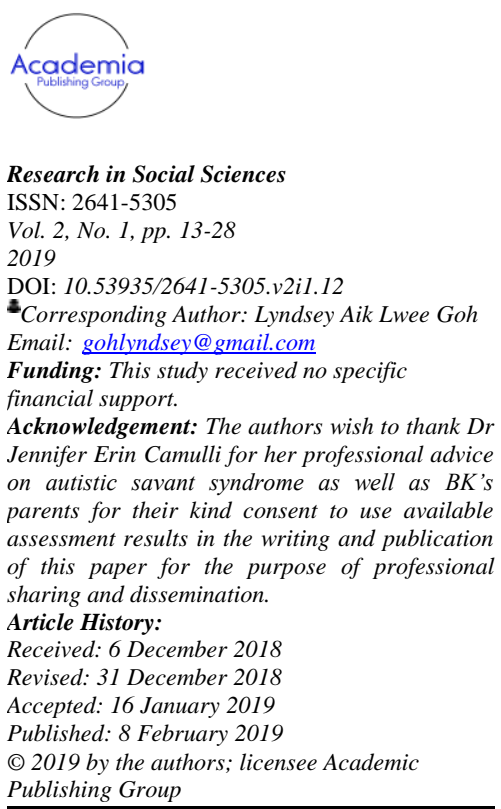

| 13

\section{Introduction}

\subsection{Tuberous Sclerosis Complex}

Tuberous sclerosis (OMIM \# 191100) with the addition of the term complex - first introduced by the pathologist Moolten (1942) - emphasizes the multisystemic involvement and variable expression of the disease, and according to the US National Library of Medicine, (2019) the tuberous sclerosis complex (TSC) "affects an estimated of one person in 6000" (para.5). The signs and symptoms of the TSC, which "may affect any human organ with well-circumscribed, benign, non-invasive lesions known as hamartias and hamartomas" (Gomez, 1987) vary from person to person. The disease can result in developmental problems and/or even can cause significant health problems to an individual with TSC, especially when it affects kidney, heart and brain.

TSC is a genetic disorder with autosomal dominant inheritance that can affect the brain, heart, skin, kidneys, lungs, and retina (Roach and Sparagana, 2004). It is characterized by the growth of numerous noncancerous (benign) tumors in different parts of the body caused by mutations in the TSC-1 and/or TSC-2 genes (Huang and Manning, 2008; Knowles, et al, 2003; Sampson, 2003). These two genes play an important role in providing genetic instructions for the making of two essential proteins - hamartin (by TSC1-1) and tuberin (by TSC-2). Within the cells, the two proteins work collaboratively together in modulating cell growth and size. Both hamartin and tuberin serve as tumor suppressors so as to prevent cells from growing and dividing too fast or in an uncontrolled way that results in tumorous growth. In other words, with the loss of these two proteins due to TSC-1 and TSC- 2 mutation, cells will grow and divide uncontrollably resulting in a 


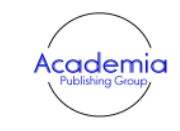

Research in Social Sciences ISSN: 2641-5305

Vol. 2, No. l, pp. 13-28

2019

DOI: 10.53935/2641-5305.v2i1.12

"Corresponding Author: Lyndsey Aik Lwee Goh

Email: gohlyndsey@gmail.com

Funding: This study received no specific

financial support.

Acknowledgement: The authors wish to thank $D r$ Jennifer Erin Camulli for her professional advice on autistic savant syndrome as well as BK's parents for their kind consent to use available assessment results in the writing and publication of this paper for the purpose of professional sharing and dissemination. Article History:

Received: 6 December 2018

Received: 6 December 2018

Revised: 31 December 2018

Accepted: 16 January 2019

(P) 2019 by 1

(C) 2019 by the authors; licensee Academic

Publishing Group tumor. The loss of hamartin or tuberin in different types of cells causes tumors in many different tissues or organs.

According to the US National Library of Medicine (2019) individuals with TSC "are born with one mutated copy of the TSC- 1 or TSC- 2 gene in each cell. This mutation prevents the cell from making functional hamartin or tuberin from the altered copy of the gene" (para.7). In about 33\% of the TSC cases, an individual can inherit an altered TSC-1 or TSC-2 gene from his/her parent who has the disease. The remaining $67 \%$ of the TSC cases happen in individuals with no history of TSC in their families.

The TSC-1 mutations are more common in familial cases of TSC while the TSC-2 mutations occur more sporadically. In fact, the TSC-2 mutation causes most cases of lymphangioleiomyomatosis (LAM for short) a devastating lung disease (characterized by the abnormal overgrowth of smooth muscle-like tissue in the lungs) that occurs almost exclusively in women, causing coughing, shortness of breath, chest pain, and lung collapse (Carsillo, Astrinidis and Henske, 2000; Chorianopoulos and Stratakos, 2008; Goncharova and Krymskaya, 2008).

Generally, all individuals with TSC have skin abnormalities, "including patches of unusually light-colored skin, areas of raised and thickened skin, and growths under the nails" (US National Library of Medicine, 2019). Tumors that appear on the face are known as facial angiofibromas and these are common at the start of the condition in childhood.

Kidney tumors are common in individuals with TSC. These tumors can affect kidney functions, resulting in serious life-threatening problems, such as end-stage renal failure (Clarke et al., 1999) acute kidney failure (Siroky, Yin and Bissler, 2010) renal angiomyolipomas (Wilson et al., 2005) pyelonephritis and polycystic kidney disease (Mohkam et al., 2014). Moreover, tumors can develop in the heart (Tuberous Sclerosis Association, 2017a) resulting in cardiac rhabdomyomas (Wilson et al., 2005) as well as tumors developing in the liver, lungs, teeth and mouth, and the light-sensitive tissue at the back of the eye (the retina) (Tuberous Sclerosis Association, 2017b).

The brain is also another vital organ that is often affected by TSC and the resulting benign (noncancerous) tumors in the brain can cause serious or life-threatening complications. There are several cerebral abnormalities associated with TSC: cortical tubers, subependymal nodules (SEN), subependymal giant cell tumors (SGCT), and white matter abnormalities such as radial bands and wedge-shaped lesions (Bozzao, Manenti and Curatolo, 2003; DiMario, 2004; Griffiths, Bolton and Verity, 1998). In many cases, TSC has caused "seizures, behavioral problems such as hyperactivity and aggression, and intellectual disability or learning problems" (US National Library of Medicine, 2019). There are also reported cases (e.g., Deweerdt, 2014; Lewis et al., 2013; Guo, Tu and Shi, 2012) of children with TSC manifesting the autistic features, such as impairment in communication and social interaction.

\subsection{Syndromic Autistic Savantism}

An estimated 17 to 61 percent of individuals with TSC manifest symptoms of autism (Asano et al., 2000). Other neurological symptoms commonly seen in such individuals also include epilepsy, intellectual disability, challenging behaviors and developmental impairment (Crino, Nathanson and Henske, 2006; Lewis et al., 2013). Several studies have shown that cortical tubers, which are developmental abnormalities of the cerebral cortex (Umeoka et al., 2008) found in individuals with TSC, are related to epilepsy and are foci for seizures. In fact, cortical tubers have been reported in $82 \%$ to $100 \%$ of people with TSC (Ridler et al., 2004).

In a study done by Gallagher et al. (2010) three types of cortical tubers, which widely vary in size, appearance and location, were identified based on the MRI signal intensity of the subcortical white matter component in individuals with TSC (see Table 1 below). 
Table-1. Three Cortical Tuber Types as identified by MRI

\begin{tabular}{ll}
\hline Tubers Type & Description \\
\hline Cortical Tuber Type \#A & $\begin{array}{l}\text { These cortical tubers are isointense on volumetric T1 images and subtly hyperintense } \\
\text { on T2 weighted and fluid-attenuated inversion recovery. }\end{array}$ \\
Cortical Tuber Type \#B & $\begin{array}{l}\text { These cortical tubers are hypointense on volumetric T1 images and homogeneously } \\
\text { hyperintense on T2 weighted and fluid-attenuated inversion recovery (FLAIR). }\end{array}$ \\
Cortical Tuber Type \#C & $\begin{array}{l}\text { These cortical tubers are hypointense on volumetric T1 images, hyperintense on T2 } \\
\text { weighted, and heterogeneous on FLAIR characterized by a hypointense central } \\
\text { region surrounded by a hyperintense rim. }\end{array}$ \\
\hline Source: Gallagher et al. (2010).
\end{tabular}

The relationship between cortical tuber features and clinical phenotype remains unclear. Based on the dominant cortical tuber types present, Gallagher et al. (2010) identified three distinct groups of people with each of the three cortical tuber types. Those with dominant Cortical Tuber Type \#A manifest a milder phenotype. Those with dominant Cortical Type \#C tuber show more MRI abnormalities (e.g., subependymal giant cell tumors) with a higher chance of having autism spectrum disorder, a history of infantile spasms, and a higher frequency of epileptic seizures, compared to those who have a dominant Cortical Tuber Type \#B, and especially to those with dominant Cortical Tuber Type \#A. However, it is not within the scope of this paper to delve on this issue.

\subsection{Tuberous Sclerosis Complex and Autism: A Possible Link?}

In a first long-term assessment of children with TSC, Jeste et al. (2014) identified early markers of autism risk in this group of individuals. It was found that children with TSC and ASD showed a gradual drop in their non-verbal intelligence between one and three years of age, while those with only TSC and without ASD did not manifest this decline (Jeste et al, 2014). As mentioned earlier above, individuals with the dominant Cortical Tuber Type \#C have a higher possibility of being diagnosed with secondary or syndromic autism and the authors of this paper inferred that it could be the case.

According to Deweerdt (2014) who cited from several other studies (i.e., Jeste et al, 2013; Landa et al., 2012; Nie, Di Nardo and Han, 2010) the findings show that children with TSC manifest developmental delays by 6 months of age and they often display difficulties with fine motor and visual skills. These infants are unable to track objects with their eyes and often disengage their attention from one object to look at another. In other words, children with TSC have structural problems in their visual system (Nie, Di Nardo and Han, 2010).. Infants diagnosed with TSC also display differences in face processing similar to those seen in ASD (Jeste et al., 2013). As a result, Jeste et al. (2014) found such early symptoms evolving into more global developmental difficulties by the time these infants were 9-12 months old. With faulty visual system, social interaction will be impaired as the infants grow and develop. One explanation is that the sensory processing abnormalities are feeding into the future social abnormalities (Jeste et al., 2014).

By the age of 3 years old, more than $50 \%$ of the participating children in the study done by Jeste et al. (2014) met the diagnostic criteria for ASD. There were also those children with TSC who did not meet the ASD criteria and the study found that this group of children also manifested social deficits. Examining the scores obtained from the assessment, Jeste et al. (2014) found that at 12 months of age, children diagnosed with TSC and AAD scored lower IQ than those with TSC alone. There was also a significant decline in nonverbal IQ over the period between one and three years.

Interestingly, the findings from Jeste's et al. (2014) study have shown that TSC may provide a model specifically of ASD that occurs along with intellectual disability (ID). The model offers a new perspective in better understanding of the relationship between ASD and ID via TSC.

\section{The Ability of Systemizing}

In a case study reported by Camulli and Goh (2018) and Camulli, Goh and Chia (2018) a young adult with TSC was found to be an autistic savant artist despite his moderate intellectual disability. According to Chia (2012) autism or ASD autism spectrum disorder (ASD) is defined as "a neuro-developmental syndrome of 


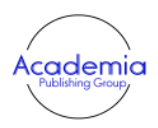

Research in Social Sciences ISSN: 2641-5305

Vol. 2, No l 1 pp. $13-28$

2019

DOI: $10.53935 / 2641-5305 . v 2 i 1.12$

"Corresponding Author: Lyndsey Aik Lwee Goh Email: gohlyndsey@gmail.com

Funding: This study received no specific financial support.

Acknowledgement: The authors wish to thank $D r$ Jennifer Erin Camulli for her professional advice on autistic savant syndrome as well as BK' parents for their kind consent to use available assessment results in the writing and publication of this paper for the purpose of professional sharing and dissemination.

Article History:

Received: 6 December 2018

Received: 6 December 2018

Revised: 31 December 2018

Accepted. 16 January 2019

Published:

(C) 2019 by the authors; licensee Academic

Publishing Group

$$
\text { | } 16
$$

constitutional origin (genetic) and whose cause could also be epigenetic, and its onset is usually around first three years of birth, with empathizing or mentalizing deficits that result in a triad of impairments in communication, social interaction, and imagination, with manifestation of repetitive stereotyped behaviors, but may, on the other hand, display (especially by autistic savants) or hide (especially by autistic cryptosavants) a strong systemizing drive that accounts for a distinct triad of strengths in good attention to detail, deep narrow interests, and islets of ability" (p.239). In other words, any individual diagnosed with ASD (be it primary, secondary or syndromic autism) can be a savant but that depends on his/her level of systemizing ability.

Talents in autism come in many forms, but a common characteristic is that the individual becomes an expert in recognizing repeating patterns in stimuli or attaining "an excellent understanding of a whole system, given the opportunity to observe and control all the variables in that system" (Baron-Cohen et al., 2009). We call this systemizing, defined as the drive to analyze or construct systems. These might be any kind of system. What defines a system is that it follows rules, and when we systemize, we are trying to identify the rules that govern the system, in order to predict how that system will behave (Baron-Cohen 2006). Here are some examples of the major kinds of system:

- Collectible systems (e.g. distinguishing between types of stones or wood);

- Mechanical systems (e.g. a video recorder or a window lock);

- Numerical systems (e.g. a train timetable or a calendar);

- Abstract systems (e.g. the syntax of a language or musical notation);

- Natural systems (e.g. the weather patterns or tidal wave patterns);

- Social systems (e.g. a management hierarchy or a dance routine with a dance partner); and

- Motoric systems (e.g. throwing a Frisbee or bouncing on a trampoline).

In addition to the abovementioned, there are still many other kinds of system including sensory systems (e.g., tapping surfaces or letting sand run through one's fingers), spatial systems (e.g., obsession with routes), vocal/auditory/verbal systems (e.g., echoing sounds), and systemizing action sequences (e.g., watching the same video repeatedly).

In other words, autistic savants are individuals with a combination of ASD and savant syndrome who display superior systemizing or hyper-systemizing abilities. However, this systemizing should be taken as "part of the cognitive style of people with autism spectrum conditions (ASC)" (Baron-Cohen et al., 2009). With superior systemizing ability in addition to a special talent possessed by an individual with ASD, "[S]avant syndrome is a rare, but extraordinary condition ... with serious mental disabilities, including autistic disorder, have some 'island of genius' that stands in marked, incongruous contrast to overall handicap" (Treffert, 2010). "The prevalence of savant syndrome is approximately $10 \%$ in the autistic population and less than $1 \%$ in the non-autistic population, making the combination rare" (Camulli, Goh, and Chia, 2018). In fact, "[S]avantism is found more commonly in ASC than in any other neurological group (Howlin, Goode and Hutton, 2009) and the majority of those with savantism have an ASC (Hermelin, 2002)" (Baron-Cohen et al., 2009). Camulli and Goh (2018) have argued that if an individual with TSC manifests autistic traits and at the same time is a savant, the condition is not savant syndrome or ASD. It should be recognized as a combination of both as a syndromic disorder to TSC. In other words, Camulli and Goh (2018) have coined the term autistic spectrum syndromic disorder to describe the comorbid condition of TSC.

\section{Background Information about the Case}

\subsection{The Case History of the Subject}

In this paper, the authors present the case of a subject - a Chinese young man, BK, currently aged 31 years old. He is the only child in the family. According to BK's medical records, he was born at 40 weeks' gestation via forceps delivery in 1986 . His weight at the time of birth was $2900 \mathrm{~g}$ and upon delivery, he underwent phototherapy to treat his severe jaundice.

When BK was about four months old, he had several bouts of fits, especially with a startle response on waking up. Later, it was followed by an increasing number of fits, having more than 5 times per day. The fits were described as "salaaming" attacks occurring when he was awake as well as when he was asleep. As a result, BK was BK was admitted to a public hospital when he was 10 months old to be treated for infantile spasm by a prominent professor of pediatrics in September 1987. BK was prescribed Prednisolone (20mg) and 


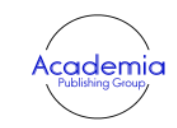

Research in Social Sciences ISSN: 2641-5305

Vol. 2, No l, pp. 13-28

2019

DOI: 10.53935/2641-5305.v2i1.12

DOI: 10.53935/2641-5305.v2il.12

Email: gohlyndsey@gmail.com

Funding: This study received no specific

financial support.

Acknowledgement: The authors wish to thank $D r$ Jennifer Erin Camulli for her professional advice on autistic savant syndrome as well as BK's parents for their kind consent to use available assessment results in the writing and publication of this paper for the purpose of professional sharing and dissemination.

Article History:

Received: 6 December 2018

Received: 6 December 2018

Revised: 31 December 2018

Accepted. 16 January 2019

Published. 8 Feb

(C) 2019 by the authors; licensee Academic

Publishing Group

$$
\text { | } 17
$$

Mogadon (a quarter of tablet). As fits began to subside, Prednisolone also started to tail off over a period of several weeks, and BK's parents did not report any further occurrences of his fits. Later, BK underwent an electroencephalogram (EEG) in July 1989. Hypsarrhythmia could be seen on the EEG. A computed tomography (CT) scan (formerly known as a computerized axial tomography scan or CAT scan) was done at the public hospital and the results revealed periventricular calcifications in his brain, especially in the left occipito-parietal region.

According to Camulli, Goh and Chia (2018) the authors reported that BK's previous medical assessment reports (dated in 1987, 1991 and 2011) from a public hospital in Singapore and another report from a hospital in Denmark, BK was diagnosed with infantile spasms (a frequent and significant cause of morbidity) with hypsarrhythmia and TSC with autistic features.

In February 1990, another EEG was administered and the results showed a spike focus on the right posttemporal occipital reaching the biparietal spreading. It was considered significant for epilepsy and for focal pathology. The EGG pattern was unchanged from the one made taken earlier in 1989.

Furthermore, three spots of achromia were found on BK's chest and near left axilla, but there were no shagreen patches or adenoma sebaceum. In addition, the medical report stated that BK's heart and lungs were clear and his abdomen was noted to be soft. There were no focal neurological signs noted, but BK was found to be developmentally delayed.

In May, 1990, BK was enrolled in a kindergarten. His mood was observed to be consistent and he was able to fit into the kindergarten. Within a few days, he was able to adapt well in the new environment. Unfortunately, he suffered a relapse of epileptic attack while in the kindergarten, and his preschool teachers described him as someone who "loses his head."

BK was noted by his preschool teachers to be a very closed-up child whose appearance and functional level were strongly characterized by his stereotyped behavior. BK spent most of his times being "private." However, there were times when he would dash about in class in a certain fixed pattern, made monotonous sounds with his mouth or with some objects, played (manipulated) with saliva either in his mouth or spat on the surface, and was very fixated by lines he could find and sun rays, etc. He also made some bizarre flicking actions with his fingers close to his eyes. BK was only able to engage very briefly with others and after that he returned quickly to his sedentary state. He reinforced and maintained his rejection of eye contact by vibrating his hands in front of his eyes and/or by screaming. On the whole, BK liked all kinds of physical activities and needed constant support of adults (i.e., his teachers and parents) during his days in the kindergarten.

Due to BK's father's job posting, the family was always on the move and it began with their first relocation in Dubai. The move was the beginning of a 15 -year global journey that the family embarked on upon the accompanying of the father's job posting as a station manager for a national airline company in different cities in Europe, Middle East and Asia, such as Dubai, Copenhagen, San Francisco, Paris, Seoul, Frankfurt, and Singapore.

With frequent re-locational changes for BK's family, there were gaps and disturbances in BK's therapeutic support schedule. Moreover, besides language barrier that BK had to cope and adapt in different countries, there were also different treatment approaches to support BK and it was overwhelming for him. Hence, at times, BK made progress, while at other times, he regressed.

In 2002, BK's family returned to Singapore. BK aged 16 by that time was able to join a local center supporting youth with autism. However, when he turned 18 years old, he could no longer be supported by center. His parents reported that he had shown a considerable regression since that time. A family's friend recommended them to have a new psycho-educational assessment done to know BK's current status and then decided how to support him and what options were available to help him to maximize his potential.

By the time when BK turned 24 years 3 months, his father had retired from work due to a rare medical condition known as syringomyelia in which a fluid-filled cyst (known as syrinx) forms within the spinal cord. As the syrinx expands and lengthens over time, it compresses and damages part of the spinal cord from its center outward. It may result in loss of feeling, paralysis, weakness, and stiffness in the back, shoulders, and extremities. 


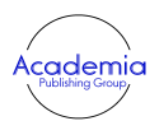

Research in Social Sciences

ISSN: 2641-5305

Vol. 2, No. l, pp. 13-28

2019

DOI: 10.53935/2641-5305.v2il.12

"Corresponding Author: Lyndsey Aik Lwee Goh

Email: gohlyndsey@gmail.com

Funding: This study received no specific

financial support.

Acknowledgement: The authors wish to thank Dr Jennifer Erin Camulli for her professional advice on autistic savant syndrome as well as BK's parents for their kind consent to use available assessment results in the writing and publication of this paper for the purpose of professional sharing and dissemination.

Article History:

Received: 6 December 2018

Revised: 31 December 2018

Revised: 61 Deccerber 2018

Accepled: 16 January 2019

(9) 2019 by the authors; licensee Academic

Publishing Group

$$
\text { | } 18
$$

3.2. Psychoeducational Diagnostic Assessment/Evaluation

3.2.1. First Set of Psychoeducational Assessment Results

In July, 1994, BK's mother requested for a psychological assessment/evaluation to be done in order to assist her in planning ahead for BK's education when the family returned to Singapore with the father from overseas attachment. Because of his developmental delay, the following several assessments were administered when he was back in Singapore: Leiter International Performance Scale-Revised (LIPS-R; Roid, et al., 1997) the Vineland Adaptive Behavior Scales-Interview Edition (VABS-I; Sparrow, Cicchetti and Balla, 1984) the Beery-Buktenica Developmental Test for Visual-Motor Integration (VMI; Beery, 1997) and the Childhood Autism Rating Scale (CARS; Schopler, Reichier and Renner, 1988). For the description for each of these assessment tools, interested readers can refer to The Special Educator's Comprehensive Guide to 301 Diagnostic Tests (Pierangelo and Giuliani, 2006).

No assessment report with quantitative data was provided. Only a descriptive write-up reporting on BK's results obtained from the cross-battery assessment (X-BA) was given. The X-BA approach uses multiple test batteries in guiding the diagnostic decision (Flanagan and McGrew, 1997) to gain a more complete understanding of BK's cognitive and behavioral abilities. The results are briefly discussed below:

\section{(1) Leiter International Performance Scale-Revised (LIPS-R)}

On the LIPS-R (Roid, et al., 1997) administration, there was little success in engaging BK. According to his psychological assessment report, BK's scores fell the standard score of 50 and that indicated that he was intellectually challenged.

(2) Vineland Adaptive Behavior Scales-Interview Edition (VABS-I)

The VABS-I (Sparrow, Cicchetti and Balla, 1984) was utilized to assess BK's adaptive functioning. Information regarding his adaptive behavior was obtained through an interview with both his classroom teacher and his mother. The results covered four domains: (i) communication, (ii) activities of daily living, (iii) socialization, and (iv) motor skills. All the four domains were reported to be in the range between Moderately Low and Low. His adaptive behavior composite was in the "Low" category. His adaptive functioning level was noted to be in the limited intellectual functioning range.

(3) Beery-Buktenica Developmental Test for Visual-Motor Integration (VMI)

BK was able to accurately draw vertical and horizontal lines in the Beery-Buktenica Developmental Test of Visual-Motor Integration (Beery, 1997). However, when BK was asked to draw a person, he could only produce scribbles (e.g., dot, single or multiple vertical lines, single or multiple horizontal lines) on the paper at the time of assessment. According to Kellogg (1970) the vertical and horizontal lines are two out of 20 basic scribbles that constitute "the building blocks of art, and they are important because they permit a detailed and comprehensive description of the work of young preschool children" (p.15). The Table 2 below lists all the 20 basic scribbles:

Table-2. The 20 Basic Scribbles.

\begin{tabular}{|c|c|c|c|}
\hline Basic Scribble & Scribble Descriptor & Basic Scribble & Scribble Descriptor \\
\hline Type 1 & Dot & Type 11 & Roving enclosing line \\
\hline Type 2 & Single vertical line & Type 12 & Zigzag or waving line \\
\hline Type 3 & Single horizontal line & Type 13 & Single loop line \\
\hline Type 4 & Single diagonal line & Type 14 & Multiple loop line \\
\hline Type 5 & Single curved line & Type 15 & Spiral line \\
\hline Type 6 & Multiple vertical line & Type 16 & Multiple-line overlaid circle \\
\hline Type 7 & Multiple horizontal line & Type 17 & Multiple-line circumference circle \\
\hline Type 8 & Multiple diagonal line & Type 18 & Circular line spread out \\
\hline Type 9 & Multiple curved line & Type 19 & Single crossed circle \\
\hline Type 10 & Roving open line & Type 20 & Imperfect circle \\
\hline
\end{tabular}

Source: Kellogg (1970) 
(4) Childhood Autism Rating Scale (CARS)

The results obtained from the CARS (Schopler, Reichier and Renner, 1988) administration showed that BK's overall score of 30 placed him in the range of mildly-to-moderately autistic condition. His highest scores (more autistic-like) were in the domains of nonverbal communication, visual response imitation, relating to people, and emotional response. His most appropriate responses were in the domains of object use, listening response, and adaptation to change. Since BK was earlier diagnosed with Tuberous Sclerosis Complex, his autistic condition was considered as syndromic autism, which means it co-exists with a medical condition as a secondary rather than primary disorder of concern (Melillo, 2012).

\subsubsection{Second Set of Psychoeducational Assessment Results}

In 2011, BK underwent two standardized assessments at the same public hospital when he was first diagnosed with TSC and syndromic autism. The two assessments were (i) Wechsler Adult Intelligence Scale$3^{\text {rd }}$ Edition (WAIS-III); and (ii) the Vineland Adaptive Behavior Scale-2 ${ }^{\text {nd }}$ Edition (VABS-2). Readers interested to know more about the two standardized assessment tools can refer to Pierangelo and Giuliani (2006) for more detail. The results are briefly described below:

\section{(1) Wechsler Adult Intelligence Scale-3rd Edition (WAIS-3)}

The WAIS-3 (Wechsler, 1997) is an individually administered clinical instrument for assessing the intellectual ability of adults aged 16 through 89 . BK did not respond to the examiner's questions at the time of assessment. He would repeat single word of the question the examiner posed. Hence, in BK's case, since he was non-verbal, it was impossible to assess him on the complete WAIS-3. Hence, there were no Verbal IQ and Full-Scale IQ could not be computed. The only result available was BK's Performance IQ of 47 at $<0.1$ percentile rank with $95 \%$ confidence interval between 43 and 57 . The result indicated that BK had an extremely low intellectual capacity.

\section{(2) Vineland Adaptive Behavior Scale-2nd Edition (VABS-2)}

The focus of VABS-2 (Sparrow, Cicchetti and Balla, 2005) is to assess the adaptive behaviors of the client, including his ability to cope with environment changes, to learn new everyday skills and demonstrate independence. The primary purpose of the VABS-2 is to assess the social abilities of an individual, whose age ranges from preschool to 90 years. The results reliably reveal crucial information for diagnosing various disabilities, including autism, Asperger syndrome, intellectual disability, and language impairment.

Since the adaptive behavior is a composite of various dimensions, the VABS-2 covers the following four sub-domains: (i) Communication; (ii) Daily Living Skills; (iii) Socialization; and (iv) Motor Skills; as well as (v) Maladaptive Behavior, which is optional. Together the v-scores obtained from the four domains a standard score can be obtained for the Adaptive Behavior Composite (ABC) score.

In BK's VABS-2 results, he scored a low ABC score of $26 \pm 7$ with <1\%ile rank. All his other VABS-2 sub-domains were in the low scores, too: $21 \pm 7$ for Communication, $46 \pm 8$ for Daily Living Skills, $23 \pm 7$ for Socialization, and $47+0$ for Motor Skills, all at $<1 \%$ ile rank.

When comparing the first set of psychoeducational assessment results with the second set, BK's intellectual quotient remained below the standard score of 50 and his adaptive behavior composite score remained in the low category. According to Meyers, Nihira and Zetlin (1979) individuals with extremely low levels of cognition, adaptive behavior tends to fall on par with cognitive ability or mental age. In other words, if cognition is significantly impaired, so are adaptive skills; however, "they tend to be equally impaired" (Saulnier and Klaiman, 2018). Saulnier and Klaiman (2018) argued that this high correlation could be accounted by two main factors: firstly, the limitations in the floor levels of assessment measures for both intellectual capacity (or IQ) and adaptive behavior; and secondly, it could be due to an overlap in behaviors being assessed at these low levels.

\subsubsection{Third Set of Psychoeducational Assessment Results}

In 2018, BK's parents sent him to a private assessment and intervention center for a new psychoeducational assessment to be done. It included the following assessments based on the XBA approach: (i) the Stanford-Binet Intelligence Scales-5th Edition (SB-5) (Roid, 2003a); (ii) the Test of Non-verbal Intelligence- $3^{\text {rd }}$ Edition (TONI-3) (Brown, Sherbenou and Johnsen, 1997) (iii) the Sensory Profile-Caregiver 
Questionnaire (SP-CQ) (Dunn, 1999); (iv) Gilliam Autism Rating Scale (GARS) (Gilliam,1995); (v) the Broad Autism Phenotype Questionnaire (BAPQ) (Hurley et al., 2007); and (vi) the Empathy Quotient (EQ) and Systemizing Quotient (SQ) Questionnaire (EQ-SQQ) (Baron-Cohen et al., 2003). The results from this set of psychoeducational assessment (see Pierangelo and Giuliani, 2006 for detail on the different standardized tests) are presented below:

\section{(1) Stanford-Binet Intelligence Scales-5th Edition (SB-5)}

The SB-5 (Roid, 2003a) has been chosen for administration as it is a wide-ranging, individually administered test battery. Its norms have been designed for age 2 through $85+$ years and its subtests cover five cognitive factors: (i) Fluid Reasoning, (ii) Knowledge (i.e., crystallized ability), (iii) Quantitative Reasoning, (iv) Visual-Spatial Processing, and (v) Working Memory - in both verbal (V) and non-verbal (NV) domains.

In BK's case, his V-IQ was 43 and his NV-IQ was 42 , both at $<0.1 \%$ ile rank and in the range $39-51$ at 95\% confidence interval. His Full-Scale IQ was 30 within the severely retarded range of 20-34 (Cooijmans, 2003). BK's NV-IQ/V-IQ profile showed that his NV-IQ was equivalent to V-IQ (i.e., NVIQ=VIQ) with only a difference by 1 point. The minimum NV-IQ/V-IQ difference of 9-10 points is required for significance at the .05 level (Roid, 2003b). BK's NV-IQ/V-IQ profile at the time of assessment was typical of individuals with extremely low intelligence. In other words, based on his SB-5 results, BK was diagnosed with intellectual and developmental disorder (Roid and Barram, 2004). A combination of the standard scores from both NV-IQ and V-IQ was used to compute the FSIQ. BK's FSIQ was 30. Since BK's FSIQ was less than 70, it indicated that he had severely impaired or delayed verbal and non-verbal skills.

During the SB-5 administration, BK also observed to have a short attention-concentration span that interfered with the testing procedure. Hence, Abbreviated Battery IQ (AbIQ), which offers a more valid estimate of BK's true intelligence, was computed as it would be more representative of the full SB-5 battery for him. The AbIQ was used in this case as its short administration time could help to minimize off-tasks behavior and maximize attention (Roid, 2003b). BK's AbIQ was 47. However, care should be taken when interpreting the AbIQ as it may overestimate true abilities (Roid and Barram, 2004). BK's FSIQ<AbIQ by a difference of 7 points. The minimum difference required for significance at the .05 level is $10-11$ points as outlined in the SB-5 Test Manual (Roid, 2003b). BK's AbIQ of 47 (at $<0.1 \%$ ile rank; 95\% confidence interval within the range of 44-60) coincided exactly with his previous Performance IQ of 47 based on the WAIS-3 administration. His NV-IQ based on the SB-5 administration was 42, just one point lower than V-IQ. His FullScale IQ based on the SB-5 administration was 40 (at $<0.1 \%$ ile rank; 95\% confidence level in the range of 37 and 45). All the standard scores were in the moderately impaired or delayed range (40-54) (Cooijmans, 2003).

\section{(2) Test of Non-Verbal Intelligence-3rd Edition (Toni-3)}

The TONI-3 (Brown, Sherbenou, and Johnsen, 1997) is designed to test non-verbal abstract/figural problem solving in several content areas: shape, position, direction, rotation, contiguity, shading, size and movement. It was administered to determine BK's non-verbal problem-solving ability in term of his deviation quotient.

BK's deviation quotient or NVIQ of 64 ((at <1\%ile rank; SEM=4); very poor) with an equivalent age of 5 years 9 months as compared with his chronological age of 31 years at the time of assessment put him in the mildly impaired or delayed range of nonverbal cognitive ability. This nonverbal standard score based on the TONI-3 administration is one level higher than the results of the standard scores based on the SB-5 administration.

\section{(3) Sensory Profile-Caregiver Questionnaire (SP-CQ)}

The SP-CQ (Dunn, 1999) was completed by BK's mother as BK was not cognitively capable of completing the Sensory Profile Self-Questionnaire himself. The aim of profile was to ascertain if Benjamin displayed any sensory-related processing, modulation and/or emotional-behavioral problems that could have interfered with his thinking/learning. Moreover, it was also to find out Benjamin's SP factors as well as the Sensory Profile summary of his sensory processing, modulation, behavior and emotional responses to external/internal stimuli.

There were two areas of concern for BK: (i) low endurance/tone, i.e., BK would prefer to be a bystander than a participator; and (ii) sedentary (i.e., a strong preference to be left alone). According to Whitney (2016) 
low endurance/tone means "lack of supportive muscle tone, usually with increased mobility at the joints; the person with low tone has limbs that are floppy, appear to not be attached to the body, and have awkward movement patterns. This lack of muscle tone results in poor ability to act in a sustained state of alert performance" (para.18).

\section{Gilliam Autism Rating Scale (GARS)}

The GARS (Gilliam,1995) is an individually-administered, norm-referenced screening measure designed in a rating scale-format. Its purpose is to identify individuals suspected with autism as well as other severe behavioral problems. The GARS measure provides an overall score known as Autism Quotient (AQ), which is computed from three or four subscales: (1) Stereotyped Behaviors; (2) Communication; (3) Social interaction; and/or (4) Developmental Disturbance.

From the GARS administration, BK's scaled scores for the four subscales were 10, 13, 8 and 10, respectively. Though all the four scaled scores were in the average range, BK performed worst in the social interaction subtest with a subscale score of 8 .

With an AQ of 102, i.e., 12 points above 90, this indicated that BK's condition included the high probability of autism. According to Jeste et al. (2014) TSC "confers a high risk of autism spectrum disorders (ASDs) and intellectual disability, with rates of ASD ranging from $25 \%$ to $60 \%$, much higher than the $1 \%$ to $2 \%$ reported in the general population" (p.160). On the reverse, Gillberg and Coleman (1996) reported an estimated $9 \%$ of children with autistic disorder have TSC. In other words, it is more common for children with TSC to have a syndromic autism than children with ASD to have tuberous sclerosis. The scaled scores of 8 through 12 or AQ of 90 through 110 on the GARS are within the average range of an individual with autism in the normative sample. According to Gilliam (1995) "Approximately 50\% of the subjects with autism scored in this range" (p.17).

\section{(4) Broad Autism Phenotype Questionnaire (BAPQ)}

The BAPQ (Hurley et al., 2007) is used to find out about a set personality and language characteristics that reflect the phenotypic expression of the genetic liability to autism, in non-autistic relatives of autistic individuals. The BAPQ includes both self-and informant-report versions. It consists of "three subscales corresponding to the triad of characteristics associated with the primary diagnostic domains of autism: (1) social abnormalities, (2) pragmatic language difficulties and (3) rigid personality and a desire of sameness" (Sasson et al., 2013).

However, in BK's case, his parents did not complete the BAPQ for reasons unknown and hence, the questionnaire was aborted or could not be used for analysis because most items were not completed.

\section{(5) Empathy Quotient-Systemizing Quotient Questionnaire for Adults}

The EQ-SQQ (Baron-Cohen et al., 2003) was developed in order to examine trends in gender typical behavior in adults. The EQ-SQQ constitutes both EQ and SQ self-report questionnaires with a Likert format and contain a list of statements about real life situations, experiences and interests where empathizing or systemizing skills are required.

Like the BAPQ, the EQ-SQQ was also aborted or could not be used for analysis because most items were not completed.

When comparing the third set of psychoeducational assessment results with the first and second sets, BK's intellectual quotient based on the SB-5 administration for both V-IQ of 43 and NV-IQ of 42 remained below the standard score of 50, but his NVIQ of 64 based on the TONI-3 administration put him in the category of mild intellectual disability. There was no adaptive behavior measure (e.g., Vineland Adaptive Behavior Scale$2^{\text {nd }}$ Edition and/or Adaptive Behavior Diagnostic Scale) done in the third set of psychoeducational assessment. Hence, there was no way to compare if cognition could be significantly more impaired than adaptive skills. BK's AQ of 102 also put in the range of high probability of autism. As mentioned earlier, "[A]pproximately $50 \%$ of the subjects in the normative sample with autism scored in this range" (Gilliam, 1995). BK's SP-CQ results indicated that he was very much a sedentary bystander than an engaging participator.

In summarizing the psychoeducational diagnosis for BK, he was a young adult diagnosed with TSC and had a comorbid condition of severely low-functioning (IQ below 50) non-verbal (lacking speech) syndromic (not primary disorder as it coexists with TSC) autistic crypto-savant (hidden talent) disorder (LF-NV-SACSD) 
or low-functioning non-verbal autistic crypto-savantism (LF-NV-ACS). Camulli and Goh (2018) used the term autistic savant spectrum syndromic disorder (ASSSD) to describe BK's condition. Table 3 provides a summary of the findings:

Table-3. A Summary of the Psychoeducational Assessment Results.

\begin{tabular}{|c|c|c|c|}
\hline Assessment Factors & $\begin{array}{l}1^{\text {st }} \text { Psychoeducational } \\
\text { assessment }\end{array}$ & $\begin{array}{l}2^{\text {nd }} \text { Psychoeducational } \\
\text { assessment }\end{array}$ & $\begin{array}{l}3^{\text {rd }} \text { Psychoeducational } \\
\text { assessment }\end{array}$ \\
\hline Year of Assessment & 1997 & 2011 & 2018 \\
\hline Intellectual Quotient & IQ $<50$ (LIPS-R) & $\mathrm{PIQ}=47(\mathrm{WAIS}-3)$ & $\begin{array}{l}\mathrm{V}-\mathrm{IQ}=43(\mathrm{SB}-5) \\
\mathrm{NV}-\mathrm{IQ}=42(\mathrm{SB}-5) \\
\mathrm{FSIQ}=30(\mathrm{SB}-5) \\
\mathrm{AbIQ}=47(\mathrm{SB}-5)\end{array}$ \\
\hline Sensory Pattern & Not available & Not available & $\begin{array}{l}\text { Low Endurance/Tone (SP- } \\
\text { CQ) } \\
\text { Sedentary (SP-CQ) }\end{array}$ \\
\hline $\begin{array}{l}\text { Adaptive Behavior } \\
\text { Quotient }\end{array}$ & $\mathrm{ABC}=$ Low $(\mathrm{VABS}-\mathrm{I})$ & $\begin{array}{l}\mathrm{ABC}=26 \pm 7(\mathrm{VABS}-2) \\
\mathrm{Com}=21 \pm 7(\mathrm{VAB}-2) \\
\mathrm{ADL}=46 \pm 8(\mathrm{VABS}-2) \\
\mathrm{Soc}=23 \pm 7(\mathrm{VABS}-2) \\
\text { Motor }=47 \pm 0(\mathrm{VABS}-2)\end{array}$ & Not available \\
\hline Autistic Quotient: & $\begin{array}{l}\text { Mild-to-moderate autistic } \\
\text { spectrum condition } \\
\text { (CARS) }\end{array}$ & Not available & $\begin{array}{l}\mathrm{AQ}=102(\mathrm{GARS}) \\
\mathrm{SB}=10(\mathrm{GARS}) \\
\mathrm{Com}=13(\mathrm{GARS}) \\
\mathrm{SI}=8 \text { (GARS) } \\
\mathrm{DD}=10(\mathrm{GARS}) \\
\text { Mild-to-moderate autism }\end{array}$ \\
\hline Concluding remarks: & $\begin{array}{l}\text { Severe intellectual } \\
\text { disability with mild-to- } \\
\text { moderate autism }\end{array}$ & $\begin{array}{l}\text { Severe } \\
\text { disability with lollectual } \\
\text { adaptive behavior skills }\end{array}$ & $\begin{array}{l}\text { Severe intellectual } \\
\text { disability with poor } \\
\text { sensory processing and } \\
\text { mild-to-moderate autism }\end{array}$ \\
\hline
\end{tabular}

The abovementioned assessment results agree to one common psychoeducational diagnosis - in addition to BK's TSC condition - of his severe intellectual disability and mild/moderate autism.

\section{Post-Assessment Discussion}

When BK was younger, he "possessed an innate ability to play piano by just listening to the tune without being taught and had even performed at a performance concert" (Camulli and Goh, 2018). His parents did not realize his savant talent and hired a piano teacher to teach him according to her method. This caused BK to be resistant and soon he lost his interest in piano playing. "Almost as soon as his musical talent was discovered, this savant ability was lost immediately. It was a clear indication of BK's early innate ability without teaching or training" (Camulli and Goh, 2018).

Several years later, BK developed a keen interest in painting, which was only noticed in 2014, when he participated in a church event to paint a mural on the side of the church car park. BK's earlier two sets of assessment results done in 1991 and 2011 indicated his severe intellectual impairment along with syndromic autism as well as all his medical diagnosis, TSC, yet, BK exhibited a special talent in painting (as well as piano playing).

An art teacher was hired to teach him. However, there was not much the art teacher could do except to facilitate and go along with BK's interest. All that could be done was to provide him with necessary tools and materials. Since then, it has become evident that BK does possess a strong systemizing ability or special talent in painting. Every piece is painted with loads of patience and more patience. It is a long process, and Camulli and Goh (2018) have described this as a manifestation of a savant artist, BK. Being identified as a savant artist, BK met the following savant traits listed by Treffert (2010):

(i) An underlying disability: BK has been diagnosed to have TSC with ID and syndromic autism as well as savant syndrome; 
(ii) An innate ability without teaching or training: BK paints without formal lessons but an art teacher was hired to facilitate his painting activities;

(iii) A talent which typically 'explodes' on the scene at a very early age, but BK's gift of painting was not known until he was an adult in his twenties. Camulli and Goh (2018) who have worked with BK before, disagreed with Treffert (2010) on this trait. They argued that very severely disabled do not exhibit their own talents which are masked, suppressed or hidden by their severe or profound disabilities;

(iv) An obsessive preoccupation with the skill: BK has an obsessive habit of picking up tiny circular items found on the ground anywhere which may not seem to be related to what savant is known for. "However, it can be regarded as an essential pre-skill that is very much required in being observant for the fine details in drawing or painting" (Camulli and Goh, 2018);

(v) A prolific output of product on a continuous basis: BK continues to demonstrate "a prolific output of product (i.e., paintings) on a continuous basis" (Camulli and Goh, 2018) over the years and has also held exhibitions for his paintings, many of which have been sold; and

(vi) A literal, eidetic-like memory with massive capacity in the area of expertise: BK possesses such a memory. For example, BK could recall the exact route his parents and/or he had taken before a long time ago, even if that had happened once, and he knew when a wrong turn was made.

All the six savant traits put forth by Treffert (2010) are re-categorized under the following three core symptoms by Camulli and Goh (2018) (see Table 4 below):

Table-4. The Three Core Symptoms of Savantism.

\begin{tabular}{|c|c|c|c|}
\hline Symptoms & First Core Symptom & Second Core Symptom & Third Core Symptom \\
\hline Descriptors & $\begin{array}{lll}\text { Presence of an } & \text { of } \\
\text { underlying disability }\end{array}$ & $\begin{array}{l}\text { One or more of the underlying } \\
\text { superior systemizing abilities } \\
\text { (Myers, Baron-Cohen, and } \\
\text { Wheelwright, 2004) }\end{array}$ & $\begin{array}{l}\text { Over-excitability in one, two or } \\
\text { more areas of extreme interests } \\
\text { (see Chia and Lim, 2017; } \\
\text { Dabrowski, 1972, for detail). }\end{array}$ \\
\hline Examples & $\begin{array}{l}\text { TSC, hyperlexia, Heller } \\
\text { 's Syndrome, etc. }\end{array}$ & $\begin{array}{l}\text { Motoric, mechanical, abstract, } \\
\text { social, natural, and organizable }\end{array}$ & $\begin{array}{l}\text { Psychomotor, sensual, intellectual, } \\
\text { emotional, and imaginational }\end{array}$ \\
\hline $\begin{array}{l}\text { Traits based } \\
\text { on Treffert's } \\
(2010) \\
\text { categories }\end{array}$ & Trait \#1 & Traits \#2, \#3 and \#6 & Traits \#4 and \#5 \\
\hline
\end{tabular}

It is the second core symptom that the authors of this paper have taken an interest to explore further in terms of the formulation of systemizing by Baron-Cohen (2006) in the following cognitive process: [input] $\rightarrow$ [operation] $\rightarrow$ [output]. To understand this 3-step process, the term system must first be understood. Baron-Cohen et al. (2003) defined a system as "something that takes inputs, which can then be operated on in variable ways, to deliver different outputs in a rule-governed way" (p.1). Generally, as already briefly described earlier, there are at least six kinds of system: (i) abstract (e.g., multiplication/repeated addition), (ii) motoric (e.g., steps involved in butterfly stroke technique in swimming), (iii) natural (e.g., soil erosion on a hillside after a thunderstorm), (iv) organizable (e.g., arranging books according to height), (v) social (e.g., a family tree or genogram), and (vi) technical (e.g., operating an electric drill). All these six systems share the same underlying process, which can be observed during systemizing: INPUT $\rightarrow$ OPERATION $\rightarrow$ OUTPUT.

Using the 3-step cognitive process, the authors examined BK's painting talent in terms of his systemizing ability in painting. BK has since produced many paintings - many of them have been sold at local arts exhibitions - and that goes to show he has an eye for detail, color texture, and stroke application (see Figure 1 to 4 below). 


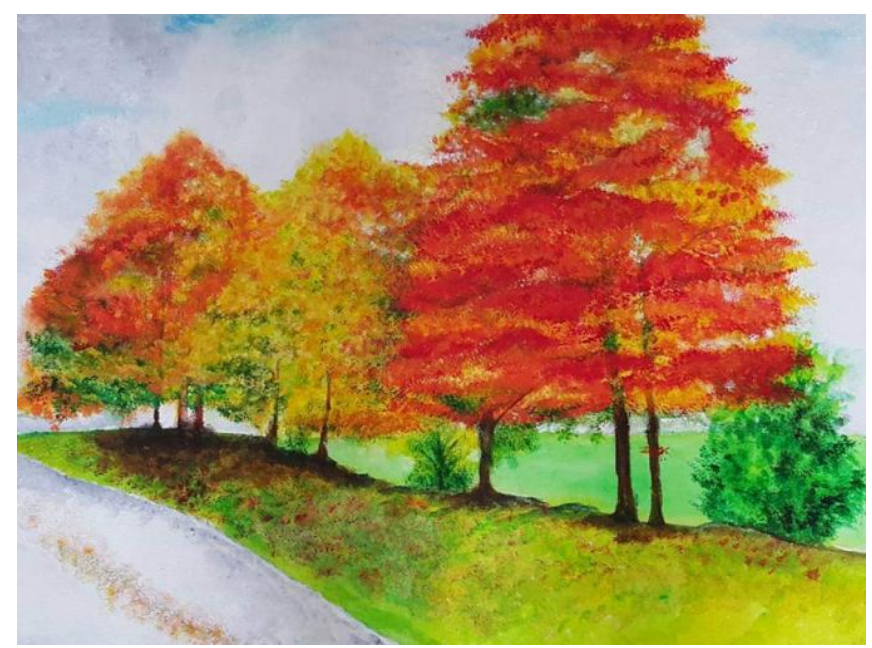

Figure-1. Trees in Autumn.

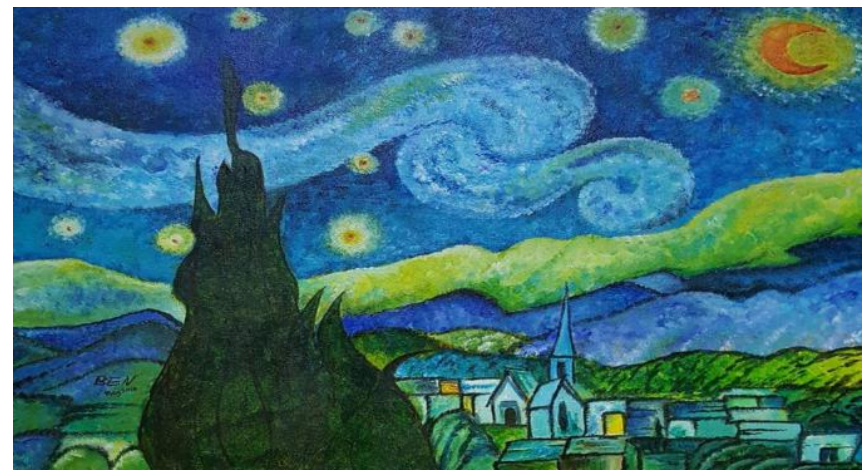

Figure-3. A Cold Silent Night.

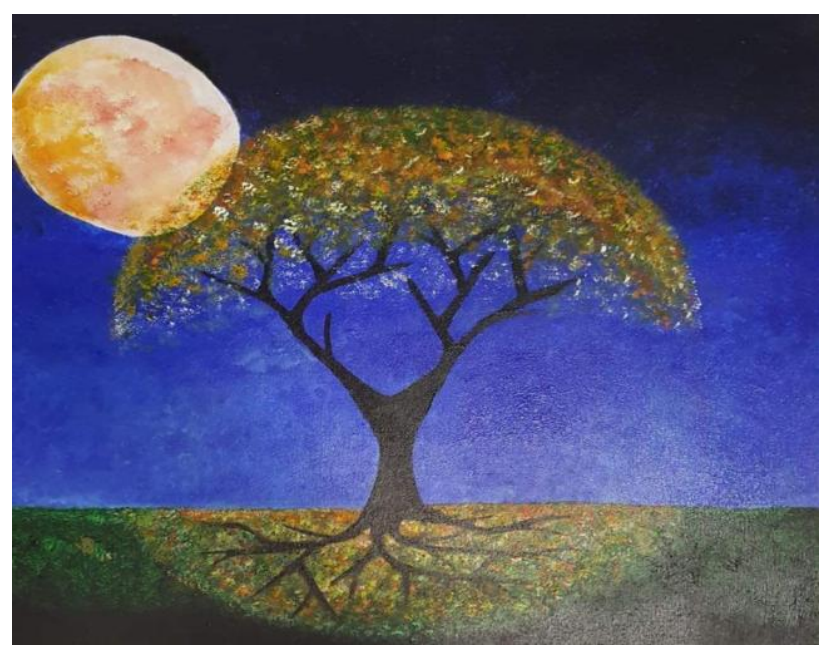

Figure-2. A Tree under the Moon.

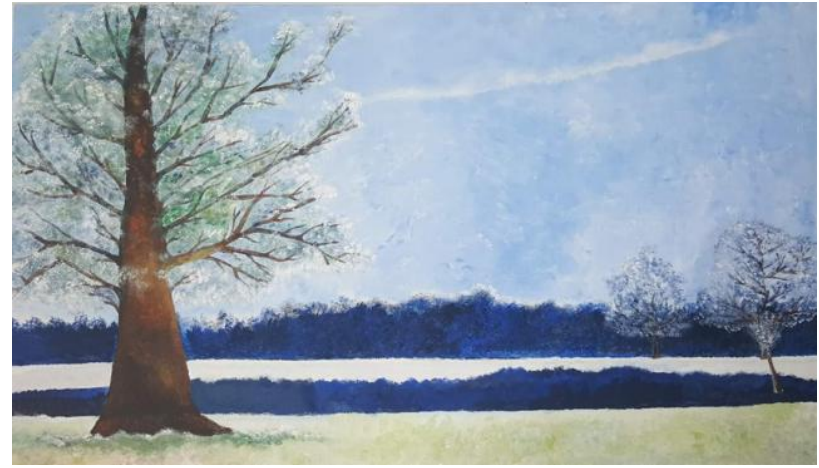

Figure-4. A Tree in Winter.

Despite his current medical conditions (i.e., TSC, ID and ASD), BK has been endowed with the ability to create by his special talent in painting. According to Simons (2004) a successful painting (using acrylics and oils) involves seven steps that constitute this specific systemizing ability:

(1) See with an observant eye for the subject to be drawn/painted;

(2) Under-paint the canvas to eliminate "the harsh, intimidating white canvas" and allow the freedom to paint in whatever way that pleases the artist;

(3) Identify the big shapes in order to organize the composition of the painting over the surface of the canvas (see Figure 5 below);

Research in So

Vol. 2, No. 1, pp. 13-28

Vol. 2 ,
2019
DOI.

DOI: 10.53935/2641-5305.v2i1.12

Corresponding Author: Lyndsey Aik Lwee Goh

Email: gohlyndsey@gmail.com

Funding: This study received no specific

financial support.

Acknowledgement: The authors wish to thank $D r$

Jennifer Erin Camulli for her professional advice on autistic savant syndrome as well as BK' parents for their kind consent to use available assessment results in the writing and publication of this paper for the purpose of professional sharing and dissemination.

Article History:

Received: 6 December 2018

Received: 6 December 2018

Revised. 31 December 2018

Accepted: 16 January 2019

(C) 2019 by the authors; licensee Academic

Publishing Group

$$
\text { |24 }
$$

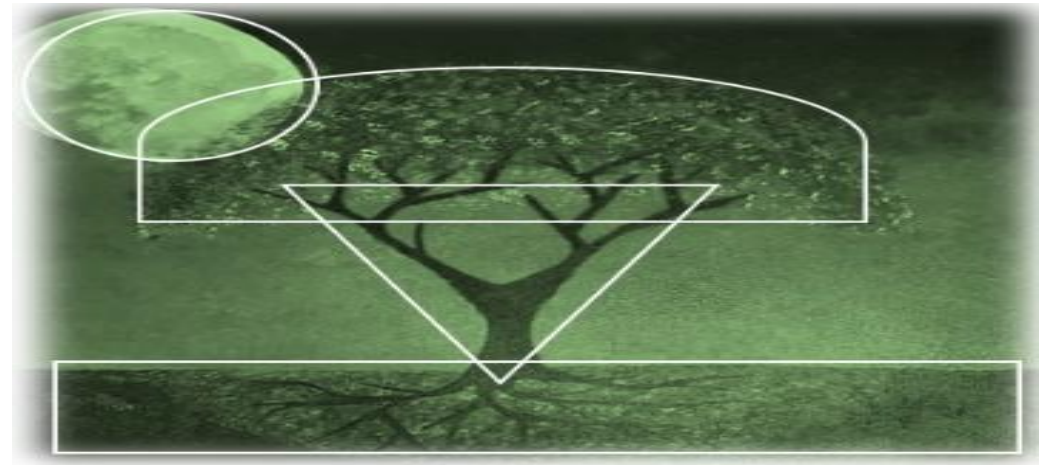

Figure-5. BK's Recognition of the Big Shapes for the Composition of His Painting. 
(4) Squint at the image that has been drawn/painted without having to see the color. In other words, "work through a value study" (Simons, 2004) i.e., starting with darkest dark and working through about five values, to the lightest (see Figure 6 below);
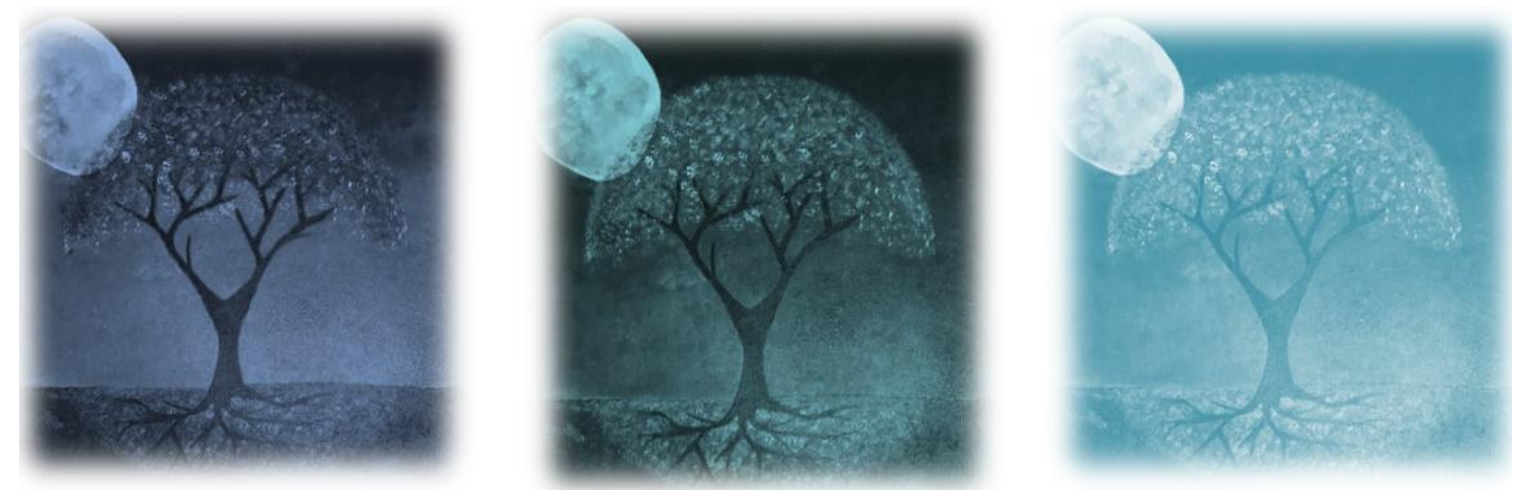

Figure-6. An Example of 3-Value Study using BK's painting of “A Tree under the Moon”.

(5) Block the colors in the painting, i.e., each color that is "put on must be same value as what is underneath it, otherwise the painting will 'collapse'!" (Simons, 2004)

(6) Adjust color and value to "make them (colors) sing" ... "Let the paint be paint - don't force it to be a tree or a flower. It has beauty in itself" (Simons, 2004); and

(7) Finish the painting, but '[R]esist the temptation to fix everything ... a good time to put on a few highlights with thick paint in the lightest areas - ever so gently lay the paint on top in one stroke without scrubbing" (Simons, 2004). The final product is shown in Figure 7 below.

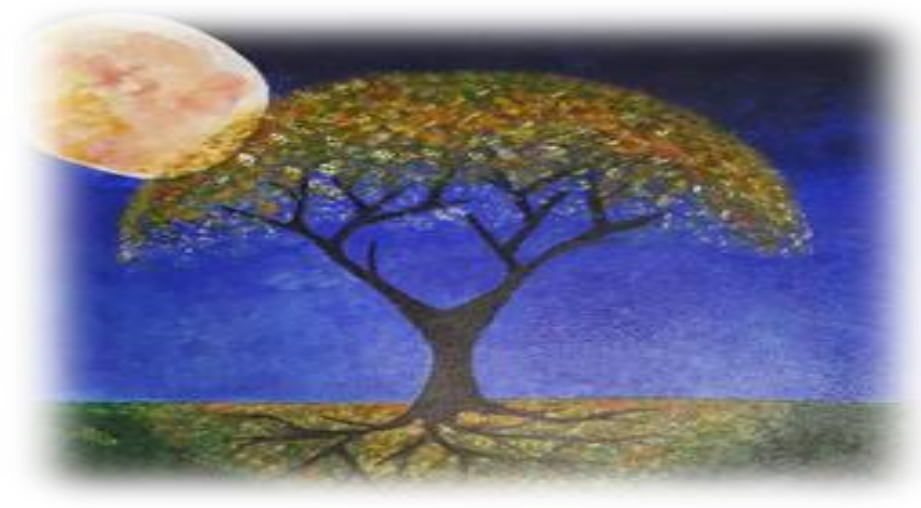

Figure-7. BK's Final Product of His Painting.

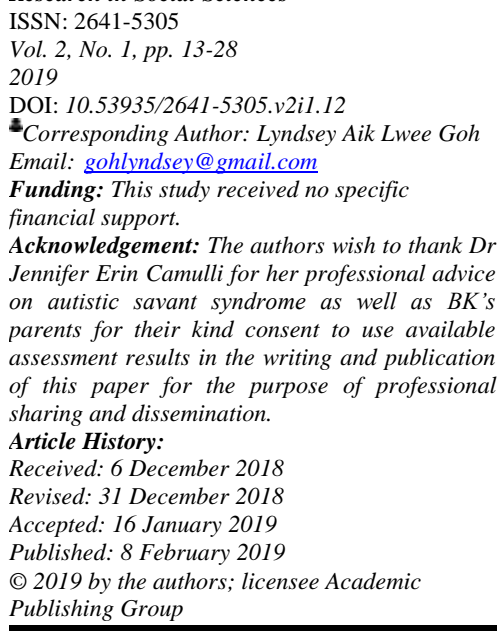

Breaking the above 7-step procedure of painting as proposed by Simons (2004) into the 3-step cognitive process of systemizing, the input $\rightarrow$ operation $\rightarrow$ output process can be presented as follows (see Figure 8 below): 


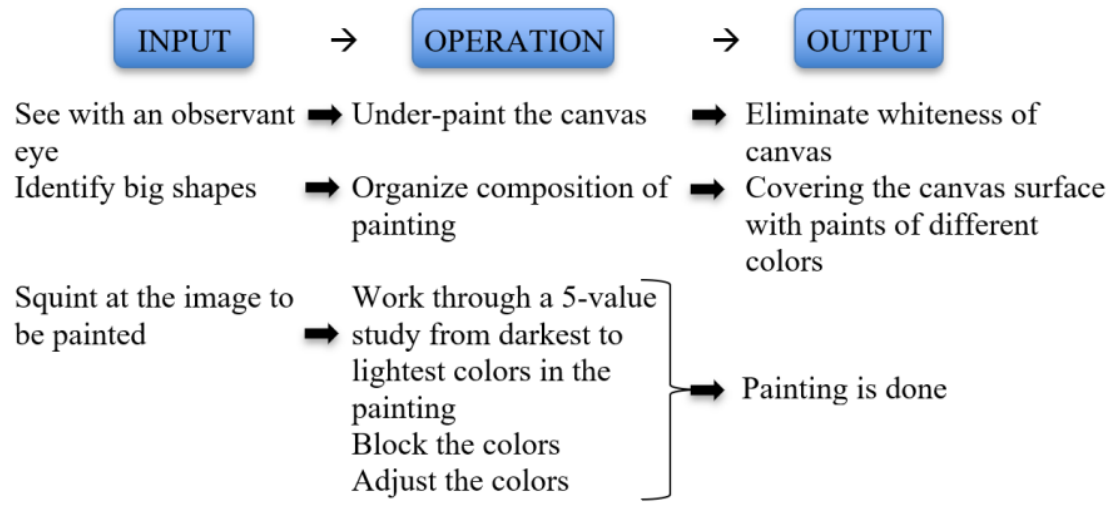

Figure-8. The Systemizing Process of Painting.

BK sees images on the internet with an observant eye and produces replicas of them through his paintings. Over a period of time, he has begun including or omitting images according to what he likes or dislikes and this habit has persisted even today, as shown in his painting. According to Camulli and Goh (2018) BK's "paintings have begun to show more interpretation in the recent months, resulting in more personalized results in his paintings" (p.199). Gradually, BK's interpretation - free form style or some other forms of creativity is expressed in his fresh, original work (Hosseini, 2012): a truly remarkable ability of a crypto-savant artist, BK's talent (despite his TSC condition with comorbid severe ID and LF/NVASD) via his systemizing ability in acrylic painting has come to light because of his/her syndromic autistic savantism.

\section{References}

Asano, E., Chugani, D.C., Muzik, O., Shen, C., Juhasz, C. \& Janisse, J. (2000). Multimodality imaging for improved detection of epileptogenic foci in tuberous sclerosis complex. Journal of Neurology, 54(10): 1976-1984.

Baron-Cohen, S. (2006). Autism: The empathizing-systemizing (E-S) theory. The year in cognitive neuroscience. Annals of the New York Academy of Sciences, 1156(1): 68-80.

Baron-Cohen, S., Ashwin, E., Ashwin, C., Tavassoli, T. \& Chakrabarti, B. (2009). Talent in autism: Hyper-systemizing, hyper-attention to detail and sensory hypersensitivity. Philosophical Transactions of the Royal Society, 364(1522): 1377-1383.

Baron-Cohen, S., Richler, J., Bisarya, D., Gurunathan, N. \& Wheelwright, S. (2003). The systemizing quotient: an investigation of adults with Asperger syndrome or high-functioning autism, and normal sex differences. Philosophical Transactions of the Royal Society of London. Series B: Biological Sciences, 358(1430): 361-374.

Beery, K.E. (1997). The beery-buktenica VMI: Developmental test of visual-motor integration with supplemental developmental tests of visual perception and motor coordination: Administration, scoring, and teaching manual. 4th Edn., Parsippany, NJ: Modern Curriculum.

Bozzao, A., Manenti, G. \& Curatolo, P. (2003). Neuroimaging. In P. Curatolo (Ed.), Tuberous sclerosis complex: From basic science to clinical phenotypes. London, UK: Mac Keith Press for the International Child Neurology Association. pp: 109-123.

Brown, L., Sherbenou, R.J. \& Johnsen, S.K. (1997). TONI-3: Test of nonverbal intelligence: A language-free measure of cognitive ability. Austin, TX: Pro-Ed.

Camulli, E.J. \& Goh, L.A.L. (2018). Re-conceptualizing autistic savantism as a spectrum syndromic disorder: A sequel to the case study of a young adult savant artist. European Journal of Special Education Research, 3(4): 185-204.

Camulli, E.J., Goh, L.A.L. \& Chia, K.H. (2018). A case study of a young adult savant artist with tuberous sclerosis complex. European Journal of Special Education Research, 3(2): 109-124.

Carsillo, T., Astrinidis, A. \& Henske, E.P. (2000). Mutations in the tuberous sclerosis complex gene TSC2 are a cause of sporadic pulmonary lymphangioleiomyomatosis. Proceedings of the National Academy of Sciences, 97(11): 6085-6090.

Chia, K.H. \& Lim, B.H. (2017). Understanding overexcitabilities of people with exceptional abilities within the framework of cognition-conation-affect-and-sensation. European Journal of Education Studies, 3(6): 649-672.

Chia, K.H. (2012). Autism enigma: The need to include savant and crypto-savant in the current definition. Academic Research International, 2(2): 234-240.

Chorianopoulos, D. \& Stratakos, G. (2008). Lymphangioleiomyomatosis and tuberous sclerosis complex. Lung, 86(4): 197-207. 
Clarke, A., Hancock, E., Kingswood, C., \& Osborne, J. P. (1999). End-stage renal failure in adults with the tuberous sclerosis complex. Nephrology, dialysis, transplantation: Official publication of the European Dialysis and Transplant Association-European Renal Association, 14(4): 988-991.

Cooijmans, P. (2003). IQ and real-life functioning. Available from: https://paulcooijmans.com/intelligence/iq_ranges.html.

Crino, P.B., Nathanson, K.L. \& Henske, E.P. (2006). The tuberous sclerosis complex. New England Journal of Medicine, 355(13): 1345-1356.

Dabrowski, K. (1972). Psychoneurosis is not an illness. London, UK: Gryf.

Deweerdt, S. (2014). Distinct features signal autism risk in tuberous sclerosis. Available from: https://www.spectrumnews.org/news/distinct-features-signal-autism-risk-in-tuberous-sclerosis/.

DiMario, J. F. J. (2004). Brain abnormalities in tuberous sclerosis complex. Journal of Child Neurology, $19(9)$ : 650-657.

Dunn, W. (1999). Sensory profile: User's manual. San Antonio, TX: Psychological Corporation.

Flanagan, D.P. \& McGrew, K.S. (1997). A cross-battery approach to assessing and interpreting cognitive abilities: Narrowing the gap between practice and cognitive science. In D.P. Flanagan, J.L. Genshaft, \& P.L. Harrison (Eds.), Contemporary intellectual assessment: Theories, tests, and issues. New York: Guilford Press. pp: $314-$ 325.

Gallagher, A., Grant, E.P., Madan, N., Jarrett, D.Y., Lyczkowski, D.A. \& Thiele, E.A. (2010). MRI findings reveal three different types of tubers in patients with tuberous sclerosis complex. Journal of Neurology, 257(8): 1373-1381.

Gillberg, C. \& Coleman, M. (1996). Autism and medical disorders: A review of the literature. Developmental Medicine and Child Neurology, 38(3): 191-202.

Gilliam, J.E. (1995). Gilliam autism rating scale (GARS): Examiner's manual. Austin, TX: Pro-Ed.

Gomez, M.R. (1987). Tuberous sclerosis. In M.R. Gomez (Ed.), Neurocutaneous diseases. A practical approach. Boston, MA: Butterworths. pp: 30-52.

Goncharova, E.A. \& Krymskaya, V.P. (2008). Pulmonary lymphangioleiomyomatosis (LAM): Progress and current challenges. Journal of Cell Biochemistry, 103(2): 369-382.

Griffiths, P.D., Bolton, P. \& Verity, C. (1998). White matter abnormalities in tuberous sclerosis complex. Acta Radiologica, 39(5): 482-486.

Guo, X., Tu, W.J. \& Shi, X.D. (2012). Tuberous sclerosis complex in autism. Iran Journal of Pediatrics, $22(3)$ : $408-411$.

Hermelin, B. (2002) Bright splinters of the mind: A personal story of research with autistic savants. London, UK: Jessica Kingsley.

Hosseini, D. (2012). The art of autism: Shifting perceptions. San Diego, CA: Art of Autism Publishers.

Howlin, P., Goode, S. \& Hutton, J. (2009). Savant skills in autism: Psychometric approaches and parental reports. Philosophical Transactions of the Royal Society B: Biological Sciences, 364: 1359-1368.

Huang, J. \& Manning, B.D. (2008). The TSC1-TSC2 complex: A molecular switchboard controlling cell growth. Biochemistry Journal, 412(2): 179-190.

Hurley, R.S., Losh, M., Parlier, M., Reznick, J.S. \& Piven, J. (2007). The broad autism phenotype questionnaire. Journal of Autism and Developmental Disorders, 37(9): 1679-1690.

Jeste, S.S., Hirsch, S., Vogel-Farley, V., Norona, A., Navalta, M.C., Gregas, M.C., Prabhu, S.P., Sahin, M. \& Nelson-III, C.A. (2013). Atypical face processing in children with tuberous sclerosis complex. Journal of Child Neurology, 28(12): 1569-1576.

Jeste, S.S., Wu, J.Y., Senturk, D., Varcin, K., Ko, J., McCarthy, B., Shimizu, C., Dies, K., Vogel-Farley, V., Sahin, M. \& Nelson-III, C.A. (2014). Early developmental trajectories associated with ASD in infants with tuberous sclerosis complex. Neurology, 83(2): 160-168.

Kellogg, R. (1970). Analyzing children's art. Mountain View, CA: Mayfield Publishing.

Knowles, M.A., Habuchi, T., Kennedy, W. \& Cuthbert-Heavens, D. (2003). Mutation spectrum of the 9q34 tuberous sclerosis gene TSC1 in transitional cell carcinoma of the bladder. Cancer Research, 63(22): 7652-7656.

Landa, R.J., Gross, A.L., Stuart, E.A. \& Bauman, M. (2012). Latent class analysis of early developmental trajectory in baby siblings of children with autism. Journal of Child Psychology and Psychiatry, 53(9): 986-996.

Lewis, W.W., Sahin, M., Scherrer, B., Peters, J.M., Suarez, R.O., Vogel-Farley, V.K., Jeste, S.S., Gregas, M.C., Prabhu, S.P., Nelson-III, C.A. \& Warfield, S.K. (2013). Impaired language pathways in tuberous sclerosis complex patients with autism spectrum disorders. Cerebral Cortx, 23(7): 1526-1532.

Melillo, R. (2012). Autism: The scientific truth about preventing, diagnosing, and treating autism spectrum disorders and what parents can do now. New York: A Penguin Group.

Meyers, C.E., Nihira, K. \& Zetlin, A. (1979). The measurement of adaptive behavior. In N.R. Ellis (Ed.), Handbook of mental deficiency, psychological theory, and research. 2nd Edn., Hillsdale, NJ: Erlbaum. pp: 70-91.

Mohkam, M., Shohadaii, S., Kompani, F., Aghadoost, H.R., Seyed, A.H.S.A. \& Nasrin, E.N. (2014). Tuberous sclerosis presenting with acute kidney failure, pyelonephritis, and polycystic kidney disease. Iranian Journal of Kidney Disease, 8(4): 336-340. 


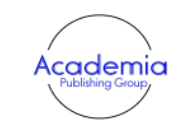

Research in Social Sciences ISSN: 2641-5305

Vol. 2, No. l, pp. $13-28$

2019

DOI: $10.53935 / 2641-5305 . v 2 i 1.12$

Corresponding Author: Lyndsey Aik Lwee Goh

Email: gohlyndsey@gmail.com

Funding: This study received no specific

financial support.

Acknowledgement: The authors wish to thank $D r$ Jennifer Erin Camulli for her professional advice on autistic savant syndrome as well as BK's parents for their kind consent to use available assessment results in the writing and publication of this paper for the purpose of professional sharing and dissemination. Article History:

Received: 6 December 2018

Received: 6 December 2018

Revised. 31 December 2018

Accepted: 16 January 2019

Published: 8 Februd

(C) 2019 by the authors; licensee Academic

Publishing Group
Moolten, S.E. (1942). Hamartial nature of tuberous sclerosis complex and its bearings on the tumor problem: Report of a case with tumor anomaly of the kidney and adenoma sebaceum. Archives of Internal Medicine, 69(4): 589-623.

Myers, P., Baron-Cohen, S. \& Wheelwright, S. (2004). An exact mind: An artist with Asperger syndrome. London, UK: Jessica Kingsley Publishers.

Nie, D., Di Nardo, A. \& Han, J.M. (2010). TSC2-RHEB signaling regulates EphA-mediated axon guidance. National Neuroscience, 13(2): 163-172.

Pierangelo, R. \& Giuliani, G. (2006). The special educator's comprehensive guide to 301 diagnostic tests. San Francisco, CA: Jossey-Bass.

Ridler, K., Suckling, J., Higgins, N., Bolton, P. \& Bullmore, E. (2004). Standardized whole brain mapping of tubers and subependymal nodules in tuberous sclerosis complex. Journal of Child Neurology, 19(9): 658-665.

Roach, E.S. \& Sparagana, S.P. (2004). Diagnosis of tuberous sclerosis complex. Journal of Child Neurology, 19(9): 643649.

Roid, G., Miller, L., Pomplun, M. \& Koch, C. (1997). Leiter international performance scale-revised. Wood Dale, IL: Stoelting Co.

Roid, G.H. \& Barram, R.A. (2004). Essentials of stanford-binet intelligence scales (SB-5) assessment. Hoboken, NJ: John Wiley \& Sons.

Roid, G.H. (2003a). Stanford-binet intelligence scales. 5th Edn., (SB-5). Itasca, IL: Riverside Publishing.

Roid, G.H. (2003b). Stanford-binet intelligence scales. 5th Edn., Examiner's manual. Itasca, IL: Riverside Publishing

Sampson, J.R. (2003). TSC1 and TSC2: Genes that are mutated in the human genetic disorder tuberous sclerosis. Biochemical Society Transactions, 31(3): 592-596.

Sasson N.J., Lam, K., Childress, D., Parlier, M., Daniels, J.L. \& Piven, J. (2013). The broad autism phenotype questionnaire: Prevalence and diagnostic classification. Autism Research, 6(2): 134-143.

Saulnier, C.A. \& Klaiman, C. (2018). Essentials of adaptive behavior assessment of neurodevelopmental disorders. Hoboken, NJ: John Wiley \& Sons.

Schopler, E., Reichler, R. \& Renner, B.R. (1988). The childhood autism rating scale. Los Angeles, CA: Western Psychological Services.

Simons, B.J. (2004). Seven steps to a successful painting. Canada: The Author (Self-Published).

Siroky, B.J., Yin, H. \& Bissler, J.J. (2010). Clinical and molecular insights into tuberous sclerosis complex renal disease. Pediatric Nephrology, 467: 1689-1695.

Sparrow, S.S., Balla, D.A. \& Cicchetti, D.V. (1984). Vineland adaptive behavior scales- interview edition: Survey form manual. Circle Pines, MN: American Guidance Service.

Sparrow, S.S., Cicchetti, D.V. \& Balla, D.A. (2005). Vineland adaptive behavior scales. 2nd Edn., Circle Pines, MN: American Guidance Service.

Treffert, D.A. (2010). Islands of genius: The bountiful mind of the autistic, acquired, and sudden savant. London, UK: Jessica Kingsley Publishers.

Tuberous Sclerosis Association, (2017a). TSC and the heart. London, UK: The Author.

Tuberous Sclerosis Association, (2017b). An introduction to tuberous sclerosis complex. London, UK: The Author.

U.S. National Library of Medicine, (2019). Tuberous sclerosis complex. Genetic home reference. Available from: https://ghr.nlm.nih.gov/condition/tuberous-sclerosis-complex\#genes.

Umeoka, S., Koyama, T., Miki, Y., Akai, M., Tsutsui, K. \& Togashi, K. (2008). Pictorial review of tuberous sclerosis in various organ. Radio Graphics, 28(7): e32. Available from: https://pubs.rsna.org/doi/pdf/10.1148/rg.e32.

Wechsler, D. (1997). Wechsler Adult Intelligence Scale. 3rd Edn., (WAIS-3). New York: Pearson Education.

Whitney, R.V. (2016). Definitions of sensory terms. Available from: http://www.spdbayarea.org/definition_of_sensory terms.htm.

Wilson, C., Idziaszczyk, S., Parry, L., Guy, C., Griffiths, D.F., Lazda, E., Bayne, R.A., Smith, A.J., Sampson, J.R. \& Cheadle, J.P. (2005). A mouse model of tuberous sclerosis 1 showing background specific early post-natal mortality and metastatic renal cell carcinoma. Human Molecular Genetics, 14(13): 1839-1850. 